\title{
A Brazilian original pedagogical approach to the teaching of neurology
}

\author{
Uma abordagem pedagógica original brasileira para o ensino da neurologia \\ Lucas Vilas Bôas Magalhães ${ }^{1}$, Paula Teixeira Fernandes², Daniel de Souza Ferreira Magalhães ${ }^{3}$, \\ Ricardo Rocha Bastos ${ }^{4}$, Li Li Min ${ }^{3}$
}

\begin{abstract}
The two-arm Clinical Decisions/Diagnostic Workshop (CD/DW) approach to undergraduate medical education has been successfully used in Brazil. Objective: Present the CD/DW approach to the teaching of stroke, with the results of its pre-experimental application and of a comparative study with the traditional lecture-case discussion approach. Method: Application of two questionnaires (opinion and Knowledge-Attitudes-Perceptions-KAP) to investigate the non-inferiority of the CD/DW approach. Results: The method was well accepted by teachers and students alike, the main drawback being the necessarily long time for its completion by the students, a feature that may better cater for different educational needs. The comparative test showed the CD/DW approach to lead to slightly higher cognitive acquisition as opposed to the traditional method, clearly showing its non-inferiority status. Conclusion: The CD/DW approach seems to be another option for teaching neurology in undergraduate medical education, with the bonus of respecting each learner's time.
\end{abstract}

Keywords: neurology, stroke, medical education, teaching materials.

\section{RESUMO}

O método Decisões Clínicas/Oficinas Diagnósticas (DC/OD) é usado com sucesso na graduação médica no Brasil. Objetivo: Apresentar o método DC/OD usando o exemplo do Acidente Vascular Encefálico, assim como os resultados de sua aplicação pré-experimental e de um estudo comparativo com o método tradicional (aula mais discussão de casos). Método: Aplicação de questionários de opiniões e de questionários de conhecimentos, atitudes e percepções para investigar a não inferioridade do método DC/OD. Resultados: DC/OD foi bem aceito por professores e estudantes. A principal crítica foi o tempo necessariamente longo para os estudantes completá-lo, característica que pode atender às diferentes necessidades educacionais. O estudo comparativo demonstrou que o método DC/OD levou a uma aquisição cognitiva maior que o tradicional, demonstrando sua não inferioridade. Conclusão: 0 método DC/OD parece ser uma alternativa para o ensino da neurologia na graduação médica, com a vantagem de respeitar o diferente tempo de aprendizado dos estudantes.

Palavras-chave: neurologia, acidente vascular cerebral, educação médica, materiais de ensino.

The last decades have witnessed a deluge of scientific evidence in all areas of neurology ${ }^{1}$. Yet, such evidence is still little applied to those who need it most, patients ${ }^{2}$, as the diagnostic acumen of primary care practitioners, chiefly in neurology, has lagged behind $d^{3,45}$. These professionals who lack the basic skills of data collection and interpretation, differential diagnosis and diagnostic work-up place a heavy burden on already over-stretched health systems ${ }^{6,7}$. Additionally, clinical inertia, which fails to implement evidence-based diagnostic tools ${ }^{8}$, makes practice predominantly replicative'. Thus, the formation of professionals who can successfully translate people's complaints into meaningful diagnoses is deficient, to say the least, calling for innovative approaches to the teaching of diagnostic reasoning (chiefly around neurological issues) in undergraduate medical education.

The teaching of neurology has been subject to a long debate in Brazil $^{10}$. The theoretical component of undergraduate medical education is mainly taught through conventional techniques (lectures, seminars and traditional case-discussions), despite evidence against the effectiveness of such approaches to teach diagnostic reasoning from

${ }^{1}$ Departamento de Medicina e Enfermagem, Universidade Federal de Viçosa, Viçosa MG, Brazil;

${ }^{2}$ Departamento de Ciências do Esporte, Faculdade de Educação Física, Universidade Estadual de Campinas, Campinas SP, Brazil;

${ }^{3}$ Departamento de Neurologia, Faculdade de Ciências Médicas, Universidade Estadual de Campinas, Campinas SP, Brazil;

${ }^{4}$ Departamento de Clínica Médica, Faculdade de Medicina, Universidade Federal de Juiz de Fora, Juiz de Fora MG, Brazil.

Correspondence: Lucas Vilas Bôas Magalhães, Departamento de Medicina e Enfermagem, Universidade Federal de Viçosa, Avenida PH Rolfs, s/n; CEP: 36570-900 Viçosa MG, Brasil; E-mail: Ivbmagalhaes@ufv.br

Conflict of interest: There is no conflict of interest to declare.

Received 06 May 2014; Received in final form 02 July 2014; Accepted 22 July 2014. 
non-specific complaints ${ }^{11,12}$. Conversely, there is a growing number of medical schools using innovative pedagogical approaches, such as Problem-Based Learning (PBL) ${ }^{13}$, Problematization $^{14}$, Team-Based Learning (TBL) ${ }^{15}$, Role play $^{16}$ and project pedagogy ${ }^{17}$, to name the most widely known. Some innovative methodologies are expensive and require complex logistics, demanding global curriculum changes and making their implementation difficult in resource-poor environments ${ }^{18}$. The reasons underlying the apparent lack of efficacy which plagues graduate medical education are manifold and poorly understood ${ }^{19}$, but we believe there is an element of disrespect for individual learning needs and tempo, besides a lack of prioritization of the teaching of diagnostic abilities from minor symptoms ${ }^{20}$.

In an attempt to improve this scenario and add value to existing and established teaching methods, an inexpensive teaching methodology was developed in Brazil: the Clinical Decisions/Diagnostic Workshops (CD/DW) approach ${ }^{21}$. Consistent with the Brazilian curriculum guidelines ${ }^{22}$, focused on the main needs of primary care, and based on modern educational principles ${ }^{23}$, with full emphasis on the development of diagnostic abilities from minor symptoms, the CD/DW begins with the choice of a topic within the general practice domain. A real clinical case is edited, with identification of several critical incidents ${ }^{24}$, which highlight the topic's importance and the need to acquire further knowledge and skills. Room is then provided for this acquisition according to the learner's need and tempo.

We chose stroke as a topic to present the CD/DW approach and to investigate its non-inferiority as compared with the traditional one.

\section{METHOD}

CD/DW material on stroke was prepared to be presented as a supplement to this article and for use in the study. Stroke was a natural choice because of its high relevance in neurology and internal medicine ${ }^{25}$. A Clinical Decisions (CD) set was then prepared, consisting of a real clinical case seen at the UNICAMP, edited for clarity in individualized parts, according to the real sequence experienced, and with key questions being posed whenever a critical incident (biological, psychological or social) called for a decision to be taken (hence the name: Clinical Decisions - CD). The printed version of the $\mathrm{CD}$ was made public at least 7 days before discussion. On the discussion day, all the participants gathered in a lecture hall and the researcher led a discussion of the case, with emphasis on answering the proposed questions. Care was taken not to work with fixed key answers, but with a construct of all the participants' contributions. The CD ended with the recognition of areas in need of learning, stroke for that matter, the whole process taking no more than 90 minutes. The second component of the CD/DW set was the diagnostic workshop (DW), a sequence of information-question stations, composed of statements, tables, graphs, pictures and sounds, developed to test and build the participants' knowledge about the topic, starting with basic definitions and classifications, proceeding through identification of relevant information, and leading to solution of complex clinical scenarios. At least 7 days before the DW was due, the students received one reference, whose reading was considered paramount before the participants attended the DW. The DW stations were displayed in a large classroom, with the participants being encouraged to physically proceed from one station to another, working individually, and taking as long as they deemed fit before moving on. The stations remained displayed during a full working day, so that the participants could attend the activity according to their individual schedules. Although the time individually spent on the DW was limitless, the participants spent, on average, 120 minutes. At the end of the process, the participants received a key to all the steps, with a wide array of commented references supporting them. Participants were then encouraged to go back to the sequence of steps, reviewing problem points. After material preparation, pre-experimental application and the comparative study were undertaken within the activities of Neurology, a subject taught in the 4th year of medical graduation at the School of Medical Sciences, UNICAMP, Brazil.

Pre-experimental application: The CD/DW about stroke set was assessed by a general practitioner, a general neurologist, and an expert neurologist in the focus sub-area. These professionals undertook a linguistic and content analysis and an assessment of the pedagogical value of the tool, also freely expressing their opinions, criticisms and suggestions, through an open written questionnaire. The set was then applied to a subgroup of 17 students, who expressed their criticisms, suggestions and opinions, also through an open written questionnaire. The researcher then further analyzed the material, incorporated the suggestions, and prepared it for the non-inferiority comparative study.

Non-inferiority comparative study: Four subgroups of students (approximately 18 students each) participated of the comparative study, with a crossover design, where the stroke topic was presented either according to the CD/DW method (two subgroups) or in a traditional way, that is, a lecture presentation followed by a traditional case-discussion (two subgroups). Each subgroup were randomly allocated to group 1 (CD/DW approach) or group 2 (traditional approach). At baseline, all participants responded a written test of Knowledge, Attitudes and Perceptions (KAP) ${ }^{26}$ on the topic of stroke, to ensure homogeneity of the samples before the intervention, and also to control for age and sex.

The students in group 1 were exposed to the CD/DW approach presented above. The students in group 2 (traditional 
method) attended a lecture on stroke, prepared, updated and delivered by a lecturer from the UNICAMP neurology division staff, with some time reserved after presentation for questions. The lecture lasted around 90-120 minutes and consisted of introduction, epidemiology, clinical subtypes of stroke, stroke in young people, laboratory tests and imaging, treatment, prognosis and prevention (primary, secondary and tertiary). Group 2 students also participated in traditional clinical-case discussion with lecturers from the neurology/neurosurgery divisions, for approximately 120 minutes.

On assessment day, all the participants sat the written KAP test again (no participant was aware that the test would be repeated), to verify cognitive acquisition. They also answered a questionnaire on their opinions about the methods experienced. During the interval between the two applications of the written KAP test (7 to 10 days), the students had no exposure to the stroke topic other than the study interventions. The researcher made sure that the whole content of the KAP test had been covered in both groups. The KAP tests were corrected according to a closed template, each participant receiving a baseline grade and another one after the intervention. The Systat 12 statistics software was used to compare grade averages: paired t-test to verify the differences in averages of each group before and after interventions, and two sample t-test, to compare the two groups before and after the intervention. The results were summarized in box-plot graphics and tables, designed with the help of the Statistical Programme Prisma software (GraphPad Prism version 5.00.288). The study was approved by the Ethics Committee in Research of FCM / UNICAMP (opinion 746/2008) and all participants gave their informed consent.

\section{RESULTS}

1) The full stroke $\mathrm{CD} / \mathrm{DW}$ is available as supplementary material to this article, allowing for easy identification of its main features and including guidelines for its replication (click the link or copy and paste into browser) http://www. medicinaviaweb.com.br/Artigos/SupplementaryMaterial.pdf.

2) Results of the pilot study (pre-experimental application). a) Below is a summary of the analysis performed by teachers and medical professionals about the stroke material:

Content was appropriate and gradually introduced, in an approach that mimics clinical practice. The stations using heart sounds were great. The teaching method was motivating and used appropriate language. However, it is very dependent on student/teacher motivation. Some teachers suggested a longitudinal follow-up.

b) Results of the analysis of the questionnaire answered by the students:

The questionnaire was answered by 17 students: $58.8 \%$ males; mean age 21 years (20-23 years, standard deviation (SD) 0.9). Regarding the CD: 3 students (17.6\%) found them excellent, nine students (52.9\%) very good, four students (23.5\%) good and one student (5.9\%) average. A representative comment of the majority opinion: "They lead us to think of several possibilities before arriving at a diagnosis". Everyone (100\%) judged that these tools facilitated their learning of medical content. Fifteen students $(88.2 \%)$ felt motivated to attend the activities, based on the preparatory reading. All students valued the feedback as an essential complementary learning step. Sixteen students (94.1\%) reported that they were motivated to seek more information after going through the CD/DW. Table 1 summarizes the students' responses.

3) Results of the non-inferiority comparative study

Group 1 (CD / DW) consisted of two subgroups, totaling 35 students: 21 (60\%) males; mean age 22 years (20-27 years, $\mathrm{SD}=1.47$ ). Group 2 (traditional) consisted of two subgroups, totaling 33 students: 15 (45.5\%) males; average age 23 years (19-30 years, $\mathrm{SD}=2.08)$.

a) Main results of the KAP questionnaire:

"Paired t" analysis; the mean difference (i.e., acquisition) in group 1 (CD/DW) was 2.07 (CI 1.63-2.51, p<0.0001) (Graph 1), and in group 2 (control) was 1.62 (CI 1.27-1.97, $\mathrm{p}<0.0001$ ) (Graph 2).

Two sample t test: there was no statistically significant difference in groups 1 and 2 at baseline (average 2.80 and 2.89, respectively. Average difference was 0.089 , 95\%CI: -0.487 to $+0.309, \mathrm{p}=0.654$ ) (Graph 3).

However, there was a slight difference in the means after the intervention (mean 4.94 and 4.46 in groups 1 and 2,

Table 1. Comparison of methods known by students (pilot study).

\begin{tabular}{|c|c|c|c|c|}
\hline Which method? & $\mathrm{CD} / \mathrm{DW}$ & Traditional lectures & Both & None \\
\hline Motivates more? & $58.8 \%$ & - & $35.3 \%$ & $5.9 \%$ \\
\hline Promotes information- seeking behavior? & $52.9 \%$ & $5.9 \%$ & $41.2 \%$ & - \\
\hline Makes planning the class? & $82.4 \%$ & - & - & $17.6 \%$ \\
\hline Allows for greater participation? & $64.7 \%$ & - & $29.4 \%$ & $5.9 \%$ \\
\hline Gives more freedom of discussion? & $29.4 \%$ & $17.6 \%$ & $52.9 \%$ & - \\
\hline Enhances learning? & $29.4 \%$ & $5.9 \%$ & $64.7 \%$ & - \\
\hline Makes thinking about the theme? & $70.6 \%$ & - & $29.4 \%$ & - \\
\hline
\end{tabular}




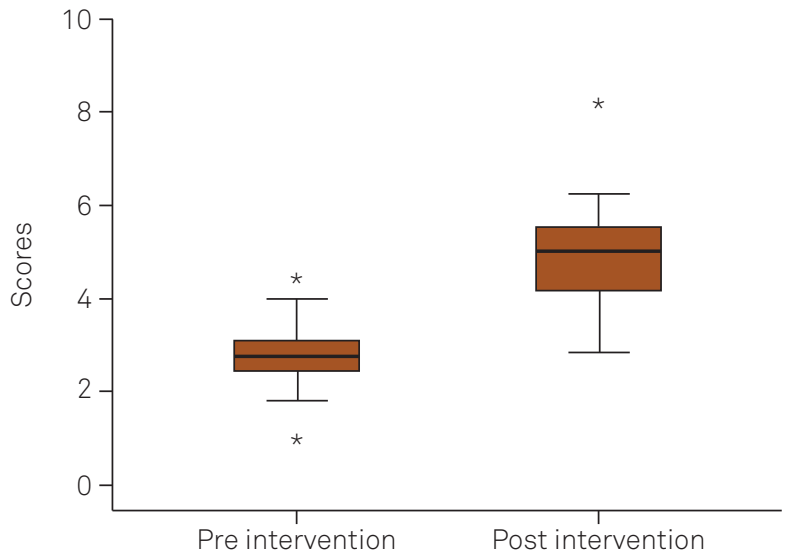

Graph 1. CD/DW group: pre (left) and post-intervention (right) grades.

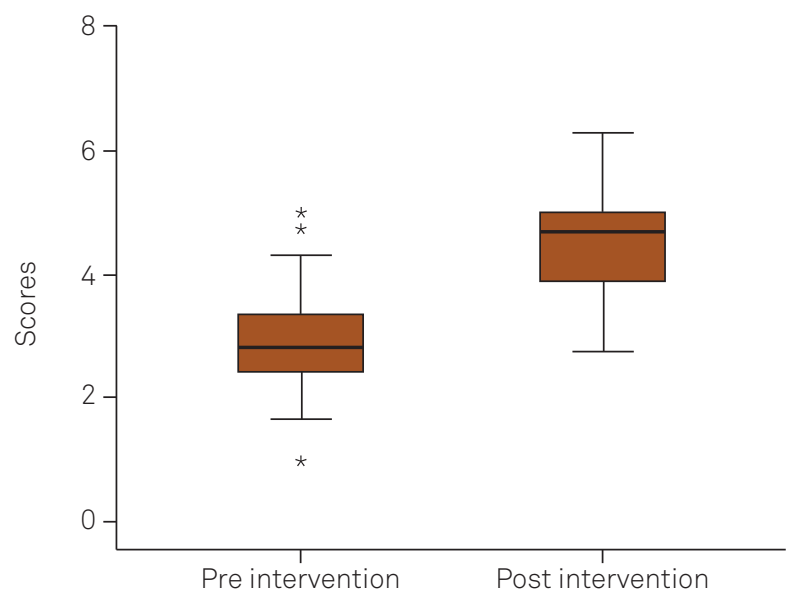

Graph 2. Control group: pre (left) and post-intervention (right) grades.

respectively. Average difference was 0.48 , CI 0.04 to 0.91 , $\mathrm{p}=0.032)$ (Graph 4).

b) Results of the analysis of the questionnaires answered by the students (non-inferiority comparative study).

Students who participated in the CD/DW method liked CD: 26 students $(74.3 \%)$ found them very good, 6 students (17.1\%) good, 2 students (5.7\%) average and one student (2.8\%) poor. 34 students $(97.1 \%)$ found the language of the $\mathrm{CD} / \mathrm{DW}$ clear and, based on their pre-reading, felt motivated to attend the activities. 33 students $(94.2 \%)$ felt that these tools facilitated their learning of the medical content. On the question "do you think you learned about the topic

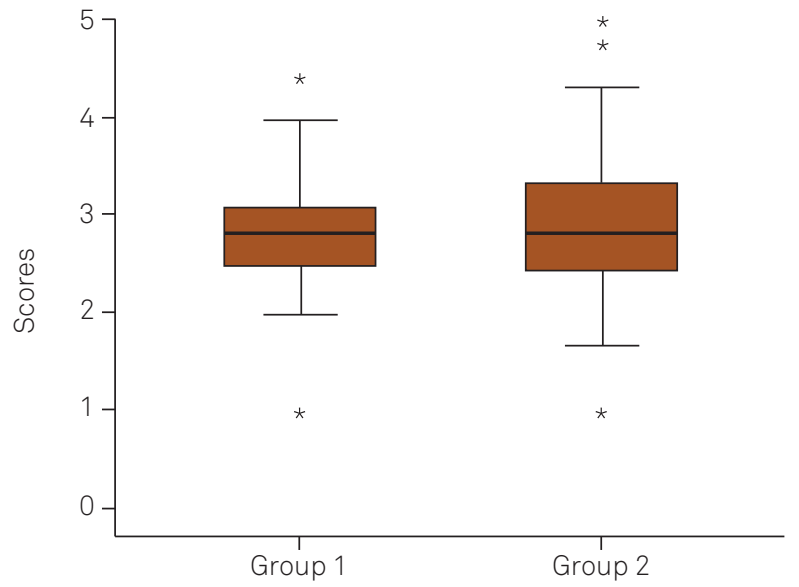

Graph 3. Groups 1 and 2 pre-intervenion.

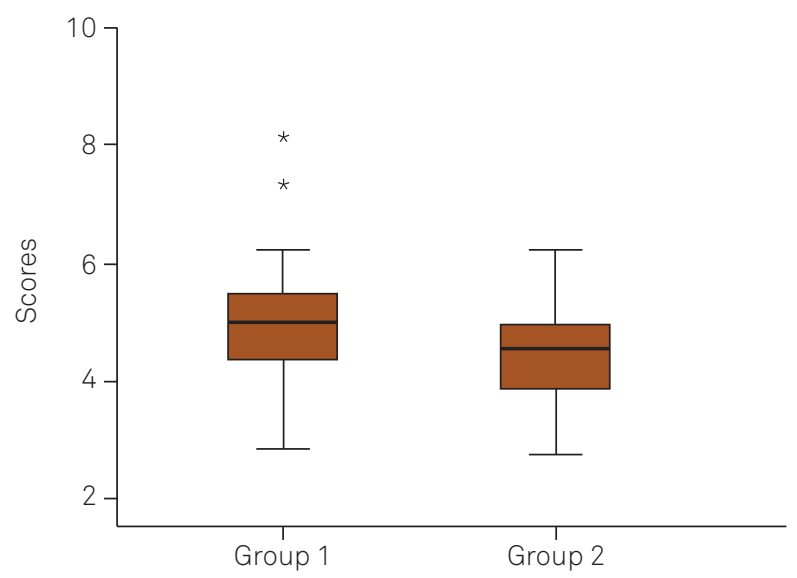

Graph 4. Groups 1 and 2 post-intervention.

presented?", 21 students (60\%) thought they had learned about the topic and 14 (40\%) thought that they had partially learned. A typical comment: "the amount of contents was very large, and the workshop was very close to the exam date, which prevented the further study suggested." 28 students (80\%) reported that they were motivated to seek more information after going through the CD/DW. The time allotted was unanimously felt to have been insufficient. Table 2 summarizes the students` responses.

Students who went through traditional activities (lecture and discussion of cases) evaluated them positively: all students rated the lecture good, clear and updated, while 32 students $(96.9 \%)$ thought that the class was comprehensive

Table 2. Comparison of the methods Known by the students (comparative study).

\begin{tabular}{|c|c|c|c|c|}
\hline Which method? & $\mathrm{CD} / \mathrm{DW}$ & Traditional lectures & Both & None \\
\hline Motivates more? & $62.8 \%$ & $8.5 \%$ & $28.5 \%$ & $0.0 \%$ \\
\hline Promotes information-seeking bahavior? & $60.0 \%$ & $14.2 \%$ & $22.8 \%$ & $2.8 \%$ \\
\hline Makes planning the class? & $80.0 \%$ & $2.8 \%$ & $14.2 \%$ & $2.8 \%$ \\
\hline Allows for greater participation? & $65.7 \%$ & $2.8 \%$ & $25.7 \%$ & $5.7 \%$ \\
\hline Gives more freedom of discussion? & $45.7 \%$ & $11.4 \%$ & $40.0 \%$ & $2.8 \%$ \\
\hline Enhances learning? & $45.7 \%$ & $11.4 \%$ & $42.8 \%$ & $0.0 \%$ \\
\hline Makes thinking about the theme? & $62.8 \%$ & $5.7 \%$ & $31.4 \%$ & $0.0 \%$ \\
\hline
\end{tabular}


and the slides adequate. 14 students $(42.4 \%)$ found the traditional discussion of cases (traditional workshop) good, 13 students (39.3\%) very good, 5 (15.1\%) excellent and 1 student $(3.03 \%)$ average. 32 students (97\%) found the language of the case discussions (traditional workshop) clear, current and understandable. 30 students (94\%) found the material appropriate.

\section{DISCUSSION}

We showed here and in the supplementary material the main pedagogical features of the CD/DW approach, using stroke as an example but with the allowance of its replication for other topics. The method may be particularly useful in underdeveloped and developing countries as it has low $\operatorname{cost}^{7,8}$. Furthermore, the CD/DW can be implemented within a single subject or even a module within a subject, as we did with stroke, requiring no global curriculum change ${ }^{21}$. The logistics requirements are minimal, compared to those required by other innovative methods. We believe that the neurology contents can be taught in eight modules (stroke, headaches, epilepsy, neuromuscular diseases, the "confused" patient, movement disorders, sleep disturbances and cerebrospinal fluid ${ }^{27}$, ideally scheduling CD for one day and leaving the DW stations on display for at least three days, so students can return the number of times they deem appropriate. Other relevant topics such as cranial trauma and nervous system tumors, for example, would be covered within the aforementioned DW, as differentials to be considered. We believe the CD/DW approach to be and active method based on the critical school ${ }^{23}$, with heavy emphasis on the development of diagnostic abilities from non-specific situations ${ }^{20}$, and capable of leading to effective knowledge building ${ }^{2}$. Commitment is a pivotal requirement for effective and solid knowledge construction here, developed through interdependent, increasingly complex stations. As explained, we believe that it is the role of the teacher to direct learning, by respecting the limits and characteristics of each individual student, something that is clearly allowed for as the time spent in the DW is individually defined. Actually, the same CD/DW set may cater for students at different moments in their graduation, since the time spent on the second arm (DW) and the number of times this arm is attempted are individually defined. Thus, ideally, each student should find room for his/her own doubts and try to solve them in an individual epiphany which is what gives sense to the learning process. The CD/DW approach has the merit of respecting the learners' individual needs and tempo.

The results of the pilot study demonstrated that the proposal was generally well-evaluated by physicians and medical educators, in terms of language, content and method. We agree that motivation is the main limiting factor for implementing this or any other innovative teaching method. However, the only change to be made to the material in the long term consists of updating the key template, as science progresses and new evidence accumulates. Thus, we believe that the CD/DW method is a great incentive to training and constant updating of real clinician-educators. The results of the questionnaires answered by the students who used the CD/DW method, either in the pilot study or in the comparative one, showed evidence that the proposal was well accepted in general terms. The vast majority commented on the lack of time to go through the DW, in a clear indication that time (as individually needed) is absolutely necessary if any meaningful learning is to occur, something other pedagogical approaches can never meet. Maybe if there were more green areas with free time to study, the CD/DW method could be more effective and would have been even better accepted. In designing the model, it was envisaged that the DW should be on display for days or even weeks, and students would return several times, after checking the corresponding key. Although we acknowledge the role of traditional lectures in organizing what may otherwise look like scattered information, we believe that strategies primarily based on patient presentation, with subsequent identification of knowledge gaps, such as the CD/DW, are the framework of undergraduate medical education ${ }^{22}$.

Regarding the results of the KAP questionnaire, it can be stated that the proposed CD/DW approach was non-inferior to the traditional one and feasible for neurological education. The KAP tests before and after the intervention allowed the analysis of the effectiveness of the CD/DW methodology as well as its comparison with the traditional method of lectures and case discussions. There was no significant difference between the averages of groups 1 and 2 at baseline, but a slight difference was statistically significant between the post intervention averages, which were higher in group 1 (CD/DW). It is worth remembering that the content taught by the $\mathrm{CD} / \mathrm{DW}$ method was not a requirement to progress in the medical undergraduate course, which may have reduced the mean differences. Perhaps, if the CD/DW were used in a subject, with formative assessments of skills and abilities to solve common problems through stations using checklists ${ }^{28}$, of course learners' participation and enjoyment could be greater, and the average difference would be likely higher.

Data from the opinion survey answered by the students in the group 2 showed that the lectures on stroke and the traditional case discussions were generally considered appropriate. These data provide a sound basis for comparisons, since they reflect that the control group was exposed to activities considered of good quality and with a schedule that was similar to that of the CD/DW group. The development of traditional activities might have been optimized because the teachers knew that students would evaluate the activities ${ }^{29}$. 
We recognize some limitations of this work. The study design was open, with cross-sectional drawings made by subgroups. A blind or double-blind approach seems impossible in this type of research. Although longitudinal follow-up, as suggested by some teachers, would clarify long-term achievement, the subjects would be exposed to different inputs to the topic studied, thus confounding any results. Because this study was conducted at a single center, further randomized and multicentric investigations could check reproducibility and enhance efficacy and cost-effectiveness analyses. We are now adapting the proposal and researching the value of the method CD/DW for Web-Based Medical Education. The method can be perfectly adapted to a virtual learning environment and is easily reproducible. So far, acceptance and results (long-term improvement of diagnostic ability) have been excellent ${ }^{30}$. We are currently developing a web-based site for neurological education with the CD/DW approach, which will make the strategy more visible and enhance its acceptance.

\section{References}

1. Nitrini R. The scientific production of Brazilian neurologists: 19952004. Arq Neuropsiquiatr. 2006;64(2B):538-42. http://dx.doi.org/ $10.1590 / \mathrm{s} 0004-282 \times 2006000300037$

2. Bastos RR. O método clínico. Juiz de Fora: Belvedere; 2013. (Coleção Céu pedrento, vol 1).

3. Martinez ARM, Nunes MB, Immich ND, Piovesana L, França M, Campos LS et al. Misdiagnosis of hemifacial spasm is a frequent event in the primary care setting. Arq Neuropsiquiatr. 2014;72(2):119-22. http://dx.doi.org/10.1590/0004-282X20130227

4. Peterson MC, Holbrook JH, Hales D, Smith NL, Staker LV. Contributions of the history, physical examination, and laboratory investigation in making medical diagnoses. West J Med. 1992;156(2):163-5.

5. Reilly BM. Physical examination in the care of medical inpatients: an observational study. Lancet. 2003;362(9390):1100-5. http://dx.doi. org/10.1016/S0140-6736(03)14464-9

6. Warren K. World Federation for Medical Education. Lancet. 1988;332(8068):462. http://dx.doi.org/10.1016/s0140-6736(88)90461-8

7. Moore G, Showstach J. Primary care medicine in crisis: toward reconstruction and renewal. Ann Intern Med. 2003;138(3):244-7. http://dx.doi.org/10.7326/0003-4819-138-3-200302040-00032

8. Straus SE, Glasziou P, Richardson WS, Haynes RB. Evidence- based medicine: how to practice and teach it. 4th ed. New York: ChurchillLivingstone; 2010.

9. Grow R, Grimshaw J. From best evidence to best practice: effective implementation of change in patients' care. Lancet. 2003;362(9391):1225-30. http://dx.doi.org/10.1016/S0140-6736(03) 14546-1

10. Pupo PP, Figueiredo JA. Ensino da neurologia. Arq Neuropsiquiatr. 1965;23(3):205-19. http://dx.doi.org/10.1590/s0004$282 \times 1965000300008$

11. Davis D, O’Brien MA, Freemantle N, Wolf FM, Mazmanian P, TaylorVaisey A. Impact of formal continuing medical education. Do conferences, workshops, rounds, and other traditional continuing education activities change physician behavior or health care outcomes? JAMA. 1999;28299):867-74. http://dx.doi.org/10.1001/jama.282.9.867

12. Evidence-based medicine working group. Evidence based medicine: a new approach to teaching the practice of medicine. JAMA. 1992;268(17):2420-5. http://dx.doi.org/10.1001/jama.268.17.2420

13. Barrows HS, Tamblyn RM. Problem-based learning: an approach to medical education. New York: Springer; 1980.

14. Berbel NAN. A problematização e a aprendizagem baseada em problemas: diferentes termos ou diferentes caminhos? Interface (Botucatu). 1998;2(2):139-54. http://dx.doi.org/10.1590/s141432831998000100008

15. Parmelee DX, Michaelsen LK. Twelve tips for doing effective Team Based Learning (TBL). Med Teach. 2010;32(2):118-22. http://dx.doi. org/10.3109/01421590903548562
16. Johansson J, Skeff KM, Stratos GA. A randomised controlled study of role play in a faculty development programme. Med Teach. 2012;34(2):e123-8. http://dx.doi.org/10.3109/0142159x.2012.644832

17. Huber M. Apprendre en projets. La pédagogie du projet-élèves. Lyon: Chronique Sociale; 2005.

18. Mennin SP, Martinez-Burrola N. The cost of problem-based versus traditional medical education. Med Educ. 1986;20(3):187-94. http://dx.doi.org/10.1111/j.1365-2923.1986.tb01166.x

19. Prober CG, Heath C. Becoming a Physician: lecture halls without lectures: a proposal for medical education. N Engl J Med. 2012;366(18):1657-9. http://dx.doi.org/10.1056/nejmp1202451

20. Benseñor IJM. Minor symptoms: the illness of the 21st century. São Paulo Med J. 2001;119(2):46-7. http://dx.doi.org/10.1590/s151631802001000200001

21. Magalhães LVB, Fernandes PT, Li LM. Aspectos educacionais na epilepsia. J Epilepsy Clin Neurophysiol. 2009;15(4):172-7. http://dx.doi.org/10.1590/S1676-26492009000400007

22. Ministério da Educação. Resolução n.4, CNE/CES de 01/11/2001. Institui diretrizes curriculares nacionais do curso de graduação em medicina. Brasília: Ministério da Educação; 2001.

23. Freire P. Pedagogia da autonomia: saberes necessários à prática educativa. 29a ed. São Paulo: Paz e Terra; 2004.

24. Flanagam JC. The critical incident technique. Psychol Bull. 1954;51(4):327-58. http://dx.doi.org/10.1037/h0061470

25. Donnan GA, Fisher M, Macleod M, Davis SM. Stroke. Lancet. 2008;371(9624):1612-23. http://dx.doi.org/10.1016/s0140-6736(08) 60694-7

26. Bunchaft G, Cavas CST. Sob medida: um guia sobre a elaboração de medidas do comportamento e suas aplicações. São Paulo: Vetor; 2002.

27. Ferri-de-Barros JE, Veiga JCE, Priante AVM, Cardoso CA, Alves FL, Ferri-de-Barros M et al. Transtornos neurológicos mais frequentes. Contribuição para a definição de temas do conteúdo programático do curso de neurologia, para a graduação médica. Ara Neuropsiquiatr. 2000;58(1):128-35. http://dx.doi.org/10.1590/S0004282X2000000100019

28. Ramaekers S, Keulen HV, Beukelen PV, Kremer W, Pilot A. Effectiveness of a programme design for the development of competence in solving clinical problems. Med Teach. 2012;34(5):e309-16. http://dx.doi.org/ 10.3109/0142159x.2012.668236

29. Adair JG. The hawthorne effect: a reconsideration of the methodological artifact. J Appl Psychol. 1984;69(2):334-45. http://dx.doi.org/ 10.1037//0021-9010.69.2.334

30. Magalhães LVB, Fernandes PT, Li LM. Como ensinar epilepsias na graduação médica? Uma proposta da Comissão de Ensino da LBE para a educação médica via web. J Epilepsy Clin Neurophysiol. 2014;20(3):94-106. 